\title{
Fomentando o respeto polo medioambiente e a reciclaxe en dous colectivos en risco de exclusión social a través do aprendizaxe-servizo
}

\author{
Abad, María José; Ares-Pernas, Ana
}

Departamento de Física e Ciencias da Terra. Campus de Ferrol. Universidade da Coruña

\section{RESUMO}

Neste traballo recóllense tres experiencias ApS realizadas no curso 2016/2017 co alumnado das materias Fundamentos de Física $\left(1^{\circ}\right.$ curso) e Deseño e Procesado con Polímeros ( $4^{\circ}$ curso) do Grado en Enxeñaría de Deseño Industrial e Desenvolvemento do Produto. 0 obxectivo era que 0 alumnado acadase certas competencias académicas e transversais da materia ao mesmo tempo que realizaba unha tarefa en beneficio de tres colectivos en risco de exclusión social; nenos/as con baixo rendemento académico, adultos desempregados e mulleres árabes. Para estes colectivos os estudantes prepararon e impartiron un taller; que no caso das nenas e dos nenos pretendía fomentar neles o respecto polo medioambiente e o pensamento crítico, no caso dos adultos formalos para a busca de emprego no sector dos plásticos e a reciclaxe e, no caso das mulleres árabes, fomentar os valores de convivencia social e o respecto polo medioambiente. 0 emprego desta ferramenta metodolóxica favoreceu a adquisición de competencias nos estudantes, a avaliación das mesmas polo docente, a relación profesor-estudante e a formación dos estudantes non só en contidos senón tamén en valores.

PALABRAS CHAVE: aprendizaxe-servizo, nenos/as, adultos, exclusión social, reciclaxe. 


\section{CITA RECOMENDADA:}

Abad, M. J., Ares-Pernas, A. (2018). Fomentando o respeto polo medioambiente e a reciclaxe en dous colectivos en risco de exclusión social a través do aprendizaxe-servizo. En E. de la Torre Fernández (ed.) (2018). Contextos universitarios transformadores: retos e ideas innovadoras. II Xornadas de Innovación Docente. Cufie. Universidade da Coruña (páx. 125-138).

DOl capítulo: https://doi.org/10.17979/spudc. 9788497496780.125

DOl libro: https://doi.org/10.17979/spudc. 9788497496780

\section{ABSTRACT}

This works includes three service-learning experiences carried out in the 2016/2017 course with students of Engineering Degree in Industrial Design and Product Development. The subjects involved in the experiences were Fundamentals of Physics (1st year) and Design and Processing with Polymers (4th year) subjects. The objective was that the students achieve certain academic and transversal skills related with the subjects and, at the same time, carried out a task for the benefit of three groups at risk of social exclusion; children with low academic performance, unemployed adults and Arabian immigrant women. For each group, the students designed and taught a workshop. In the case of children, it was intended to encourage them environment respect and critical thinking; in the case of adults, to train them for searching job in plastic and recycling industries and in the case of arabian women, promote the values of social coexistence and environment respect. This methodology favoured skill acquisition in the students, the assessment by teacher, the teacher-student relationship and the training of students not only in content but also in values.

KEY WORDS: service-learning, children, adults, social exclusion, recycling. 


\section{INTRODUCIÓN}

A Universidade ademais de formar ao estudante no eido profesional debe tamén fomentar a súa responsabilidade como cidadán nunha sociedade democrática e máis xusta (UNESCO 1998, UNESCO 2009). Concretamente a educación no campo da enxeñaría parece orientarse á crecente importancia do contexto social nesta titulación. 0 aprendizaxe-servizo (ApS) é unha ferramenta educativa que se está a empregar neste campo coa intención de mellorar as capacidades de liderado e de crear cidadáns e profesionais globais, socialmente responsables. Hai numerosos estudios que apoian esta metodoloxía para formar enxeñeiros con estas características (Latib 2017, Dienhart 2016).

Mediante 0 emprego desta metodoloxía os estudantes son responsables do seu propio aprendizaxe, traballan competencias transversais como a capacidade para 0 deseño e redacción de proxectos, a comunicación efectiva ou falar en público. Foméntase o traballo en grupo, a aprendizaxe colaborativa e cooperativa, a autoavaliación e facilitase 0 proceso de avaliación do profesor, que fai de guía e observador dos estudantes durante todo o proxecto. Existen outras metodoloxías que permiten traballar estas competencias como a aprendizaxe baseada en problemas ou en proxectos, sen embargo o ApS ten un valor engadido, pois os estudantes realizan ao mesmo tempo un servicio á comunidade, o que fai da metodoloxía unha ponte perfecta para unir a aprendizaxe de contidos, competencias e valores (Puig 2008, Ferrán-Xubillaga \& Guinnot-Viciano 2012, Rubio 2009).

A actividade que se presenta neste traballo, tiña como obxectivo que os estudantes das materias Fundamentos de Física ( $1^{\circ}$ curso) e Deseño e Procesado con Polímeros ( $4^{\circ}$ curso) do Grado en Enxeñaría de Deseño Industrial e Desenvolvemento do Produto puxesen en práctica conceptos da Reciclaxe de Plásticos previamente explicados na aula. Ao mesmo tempo, os estudantes poderían realizar unha actividade en beneficio da comunidade, que se materializou nun taller impartido a un grupo de nenas/os e a dous grupos de adultos todos en risco de exclusión social. 0 grupos, de perfís moi diferentes, presentaban necesidades distintas, previamente identificadas por Cáritas Diocesana de Mondoñedo- Ferrol e que se 
intentaron cubrir coa realización da actividade ApS. Os/as nenos/as presentaban baixo rendemento académico e os adultos eran fundamentalmente desempregados en busca de formación. No traballo inclúese todo 0 procedemento seguido para a implantación da actividade dentro das materias involucradas, dende a detección da necesidade por parte da comunidade, 0 deseño da actividade, as competencias que debe adquirir 0 alumnado e 0 servicio que deben prestar, así coma un análise final que abarcou a todos os axentes involucrados no ApS.

\section{DESCRICIÓN DA EXPERIENCIA}

\subsection{Planificación das actividades ApS}

Esta actividade desenvolveuse entre os meses de Setembro e Xaneiro do curso 2016/2017 co alumnado da materia Deseño e Procesado con Polímeros (DPP), de $4^{\circ}$ curso do Grao en Enxeñaría en Deseño Industrial e Desenvolvemento do Produto da Universidade da Coruña (UDC), e entre os meses de Febreiro e Xuño do mesmo curso cos estudantes da materia Fundamentos de Física (FF) da mesma titulación.

A actividade ApS empezou a artellarse a partir dunha reunión entre as profesoras responsables das materias e a entidade Cáritas Diocesana de Mondoñedo Ferrol, na que se fala da existencia dos tres grupos de usuarios. Por unha banda, un grupo de nenos/as en risco de exclusión social, que forman parte do programa "Medrando en Familia" da entidade, e que presentan un baixo rendemento académico e un desinterese total polo estudo das ciencias motivado en parte pola situación na que viven. Por outra banda dous grupos de adultos, un grupo de homes e mulleres desempregados que pertencen ao "Programa de Emprego" da entidade e un grupo de mulleres árabes que participan no "Taller de Costura" da mesma entidade. A entidade transmítelles ás profesoras a necesidade de fomentar nos/as nenos/as 0 interese pola ciencia e pola protección do medioambiente, no caso dos adultos, a necesidade dalgunha formación para a busca de emprego e, no das mulleres árabes, a integración destas na comunidade. Con esta idea en mente, propónselle ao alumnado a posibilidade de participar 
nunha actividade ApS, realizando un servicio a esa comunidade e que ese traballo sexa substitutivo do que habitualmente realizan na materia, prácticas de laboratorio, no caso de Fundamentos de Física (FF), ou un traballo tutelado, onde estudan a fabricación dun obxecto innovador en materiais plásticos, no caso de Deseño e Procesado con Polímeros (DPP). A resposta por parte dos estudantes foi moi boa, e houbo de seleccionar os participantes por sorteo. A composición dos grupos, o número de usuarios participantes e o servizo a realizar figuran na Táboa 1 de xeito resumido.

\begin{tabular}{|c|c|c|c|}
\hline & Nenos/as & Adultos & Mulleres árabes \\
\hline $\mathrm{N}^{0}$ estudantes & 8 & 10 & 6 \\
\hline Materia & $\mathrm{FF}$ & DPP & DPP \\
\hline Cuadrimestre & $2^{0}$ & $1^{0}$ & $1^{0}$ \\
\hline Curso & $1^{0}$ & $4^{0}$ & $4^{0}$ \\
\hline $\mathrm{N}^{0}$ de usuarios & 23 & 20 & 8 \\
\hline $\begin{array}{l}\text { Características } \\
\text { usuarios }\end{array}$ & $\begin{array}{c}\text { Fracaso escolar } \\
\text { Baixa autoestima } \\
\text { Desinterese polos } \\
\text { estudos }\end{array}$ & $\begin{array}{c}\text { Desemprego } \\
\text { Desmotivación } \\
\text { Baixa autoestima }\end{array}$ & $\begin{array}{c}\text { Desemprego } \\
\text { Falta de integración na } \\
\text { comunidade }\end{array}$ \\
\hline Necesidade & $\begin{array}{l}\text { Mellorar o rendemento } \\
\text { académico e a } \\
\text { motivación. } \\
\text { Promover o gusto polas } \\
\text { ciencias }\end{array}$ & $\begin{array}{l}\text { Formación para a busca } \\
\text { de emprego }\end{array}$ & $\begin{array}{c}\text { Educación en valores de } \\
\text { convivencia social na } \\
\text { familia }\end{array}$ \\
\hline Servizo & $\begin{array}{c}\text { Educación } \\
\text { medioambiental. } \\
\text { Reciclaxe e reutilización }\end{array}$ & $\begin{array}{l}\text { Formación reciclaxe de } \\
\text { plásticos para a busca de } \\
\text { emprego nese sector }\end{array}$ & $\begin{array}{c}\text { Educación } \\
\text { medioambiental. } \\
\text { Reciclado e reutilización }\end{array}$ \\
\hline
\end{tabular}

Táboa 1. Descrición das experiencias ApS

Unha vez fixado o servizo era importante analizar se este cumpría os obxectivos da aprendizaxe, xa que a actividade debe estar perfectamente deseñada nos dous aspectos: non será ApS senón hai servizo á comunidade, pero tampouco será ApS senón están perfectamente artellados os obxectivos da aprendizaxe. Ademais da conexión cos conceptos teóricos, que é máis que evidente nas dúas materias, as competencias que se traballarían na parte práctica de FF e DPP son as mesmas que se van a traballar coa experiencia ApS e que 
figuran de xeito resumido na primeira columna da rúbrica da Táboa 2. Estas competencias e a actividade en si obviamente están reflexadas na guía docente das materias.

\begin{tabular}{|c|c|c|c|c|}
\hline \multicolumn{5}{|c|}{ Actividade Aprendizaxe- Servizo - Avaliación de grupos } \\
\hline Criterio (puntos) & $\begin{array}{l}\text { Non cumpre } \\
\text { (0 puntos) }\end{array}$ & $\begin{array}{l}\text { Cumprimento } \\
\text { insuficiente } \\
\text { (1 punto) }\end{array}$ & $\begin{array}{c}\text { Cumprimento } \\
\text { suficiente (2 puntos) }\end{array}$ & $\begin{array}{l}\text { Cumprimento } \\
\text { excelente } \\
\text { ( } 3 \text { puntos) }\end{array}$ \\
\hline $\begin{array}{l}\text { 1.Traballar de } \\
\text { forma efectiva } \\
\text { como membro } \\
\text { equipo (A4) }\end{array}$ & $\begin{array}{c}\text { Non se realiza } 0 \\
\text { traballo }\end{array}$ & $\begin{array}{c}\text { Realizase o traballo } \\
\text { a medias }\end{array}$ & $\begin{array}{l}\text { Realizase o traballo } \\
\text { pero non no prazo } \\
\text { acordado }\end{array}$ & $\begin{array}{c}\text { Realizase o traballo } \\
\text { e cúmprense os } \\
\text { prazos }\end{array}$ \\
\hline $\begin{array}{c}\text { 2.Capacidade } \\
\text { deseño, redacción } \\
\text { e dirección... (A7) }\end{array}$ & $\begin{array}{c}\text { Os/as alumnos/as } \\
\text { non buscan a } \\
\text { información axeitada } \\
\text { e non saben } \\
\text { sintetizala }\end{array}$ & $\begin{array}{l}\text { 0a/as alumnos/as } \\
\text { buscan a } \\
\text { información } \\
\text { axeitada pero non } \\
\text { saben sintetizala }\end{array}$ & $\begin{array}{l}\text { Os/as alumnos/as } \\
\text { buscan a información } \\
\text { axeitada e sintetízana } \\
\text { de xeito aceptable }\end{array}$ & $\begin{array}{l}\text { Os/as alumnos/as } \\
\text { buscan a } \\
\text { información axeitada } \\
\text { e presentan un bo } \\
\text { proxecto }\end{array}$ \\
\hline $\begin{array}{l}\text { 3. Traballar de } \\
\text { forma colaborativa } \\
\text { (B4) }\end{array}$ & $\begin{array}{l}\text { 0s/as alumnos/as } \\
\text { non se integran no } \\
\text { grupo e teñen } \\
\text { problemas para } \\
\text { interaccionar } \\
\text { cos/oas usuarios/as } \\
\text { da entidade }\end{array}$ & $\begin{array}{l}\text { Os/as alumnos/as } \\
\text { non se integran } \\
\text { como grupo pero } \\
\text { traballan ben } \\
\text { cos/oas usuarios/as } \\
\text { da entidade }\end{array}$ & $\begin{array}{l}\text { Os/as alumnos/as } \\
\text { intégranse como } \\
\text { grupo pero teñen } \\
\text { problemas para } \\
\text { interaccionar cos/oas } \\
\text { usuario/as da } \\
\text { entidade }\end{array}$ & $\begin{array}{l}\text { Os/as alumnos/as } \\
\text { intégranse como } \\
\text { grupos e traballan } \\
\text { moi ben cos/oas } \\
\text { usuarios/as da } \\
\text { entidade }\end{array}$ \\
\hline $\begin{array}{l}\text { 4.Comunicarse de } \\
\text { maneira efectiva } \\
\text { nun entorno de } \\
\text { traballo (B9) }\end{array}$ & $\begin{array}{l}0 \text { grupo non mantén } \\
\text { contacto nin coas } \\
\text { titoras nin dentro do } \\
\text { grupo }\end{array}$ & $\begin{array}{c}0 \text { grupo } \\
\text { comunícase de } \\
\text { forma efectiva entre } \\
\text { si pero non coas } \\
\text { titoras }\end{array}$ & $\begin{array}{l}0 \text { grupo comunícase } \\
\text { coas titoras pero hai } \\
\text { problemas de } \\
\text { comunicación dentro } \\
\text { do grupo }\end{array}$ & $\begin{array}{l}0 \text { grupo } \\
\text { comunícase ben } \\
\text { entre sí e coas } \\
\text { titoras }\end{array}$ \\
\hline $\begin{array}{l}\text { 5.Expresarse } \\
\text { correctamente } \\
\text { (C1) }\end{array}$ & $\begin{array}{c}0 \text { grupo ten } \\
\text { problemas para falar } \\
\text { en público e } \\
\text { adaptarse ao } \\
\text { auditorio } \\
\end{array}$ & $\begin{array}{l}0 \text { grupo non ten } \\
\text { problemas para } \\
\text { falar en público } \\
\text { pero non se adapta } \\
\text { ao auditorio }\end{array}$ & $\begin{array}{c}0 \text { grupo ten } \\
\text { problemas para falar } \\
\text { en público pero é } \\
\text { capaz de adaptarse } \\
\text { ao auditorio }\end{array}$ & $\begin{array}{c}0 \text { grupo fala ben en } \\
\text { público e adáptase } \\
\text { perfectamente ao } \\
\text { auditorio }\end{array}$ \\
\hline 6. Cidadanía (C4) & $\begin{array}{l}0 \text { grupo non ten } \\
\text { interese na entidade } \\
\text { nin na repercusión } \\
\text { do seu traballo }\end{array}$ & $\begin{array}{l}0 \text { grupo ten interese } \\
\text { en traballar coa } \\
\text { entidade pero non } \\
\text { se involucra o } \\
\text { suficiente }\end{array}$ & $\begin{array}{c}0 \text { grupo non ten } \\
\text { interese en traballar } \\
\text { coa entidade pero si } \\
\text { se preocupa pola } \\
\text { repercusión do seu } \\
\text { traballo }\end{array}$ & $\begin{array}{c}0 \text { grupo ten interese } \\
\text { en traballar coa } \\
\text { entidade e } \\
\text { preocupase da } \\
\text { repercusión do seu } \\
\text { traballo }\end{array}$ \\
\hline
\end{tabular}

Táboa 2. Rúbrica de avaliación de competencias 
Tralo deseño da actividade ApS fixouse o cronograma da actividade que quedou coma segue:

- Semana 1-10: Deseño dos materiais, xogos, experimentos, presentacións, etc... Sesións de titorización e revisión.

- Semana 11-12: Ensaio final.

- Semana 13: Realización dos talleres cos usuarios das entidades.

Por último, é imprescindible deseñar o procedemento de avaliación e que este sexa claro para os estudantes na parte que lles aplica. Os procedementos de avaliación tanto dos estudantes coma da actividade foron os seguintes:

- Dende o punto de vista académico: A avaliación de competencias realizouse mediante o emprego dunha rúbrica (Táboa 2). Esta rúbrica empregouse durante todo o proceso para ir avaliando a adquisición de competencias polo estudante e polo grupo durante 0 desenvolvemento da actividade.

- Dende o punto de vista cuantitativo: Ao final da actividade fíxose unha enquisa a todos os axentes involucrados: estudantes, usuarios, comunidade e profesores. Na enquisa preguntábaselles acerca de aspectos tales coma a adecuación da convocatoria, os obxectivos, a duración, intensidade e organización, así como a satisfacción coa titorización, etc... dependendo do caso. 0 obxectivo final desta análise é a detección de puntos fortes e débiles para, de ser necesario, redeseñar a actividade de cara a vindeiros cursos.

- Dende 0 punto de vista cualitativo: recolléronse as reflexións dos estudantes en distintos puntos da actividade. Ao inicio preguntóuselles pola súa motivación para participar na actividade, as súas expectativas, as súas preocupacións, etc... e fóronse recollendo os cambios nas súas impresións de forma escrita, en distintos puntos da actividade. Ademais ao final da actividade realizáronse reunións profesores/estudantes, profesores/entidade para analizar tamén os puntos fortes e débiles da actividade. 


\subsection{Desenvolvemento das actividades ApS}

Actividade 1: Nenos/as en risco de exclusión social

Na primeira parte da actividade, os estudantes que participaron neste grupo explicaron aos/ás nenos/as cuestións xerais sobre plásticos e a súa identificación, faláronlles do deterioro do medioambiente, de redución, reutilización e reciclaxe e de separación de residuos. Os estudantes deseñaron xogos que intercalaban coa explicación de conceptos (Figura 1) con un dobre obxectivo; manter a atención dos/as nenos/as e comprobar se estaban asimilando os contidos do taller. Na segunda parte do taller fabricaron novos obxectos reutilizando plásticos (envases, botellas), por exemplo fabricaron estoxos en forma de mazá ou coches autopropulsados con botellas de plástico ou incluso un lapiseiro con tapóns de botellas. $\mathrm{Na}$ Figura 2 poden verse algúns deses obxectos. 0s/as nenos/as implicáronse moito na actividade e participaron activamente en todos os xogos.
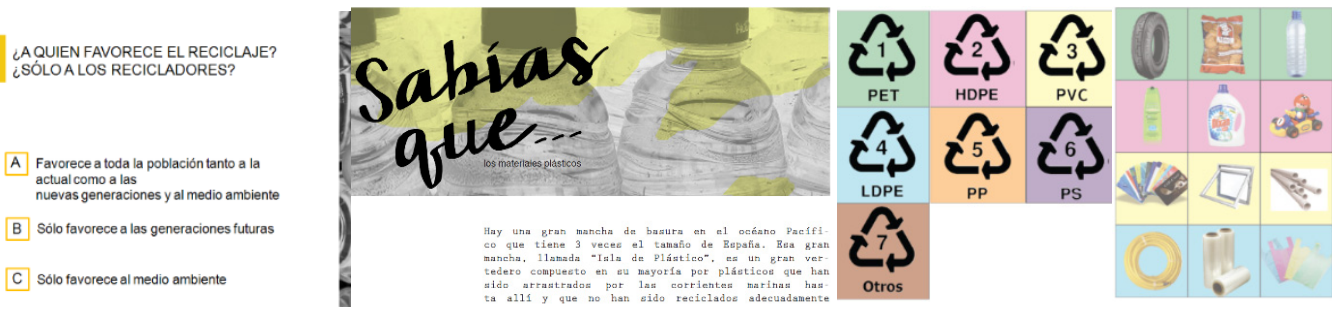

Figura 1. Xogos deseñados polos estudantes para o taller

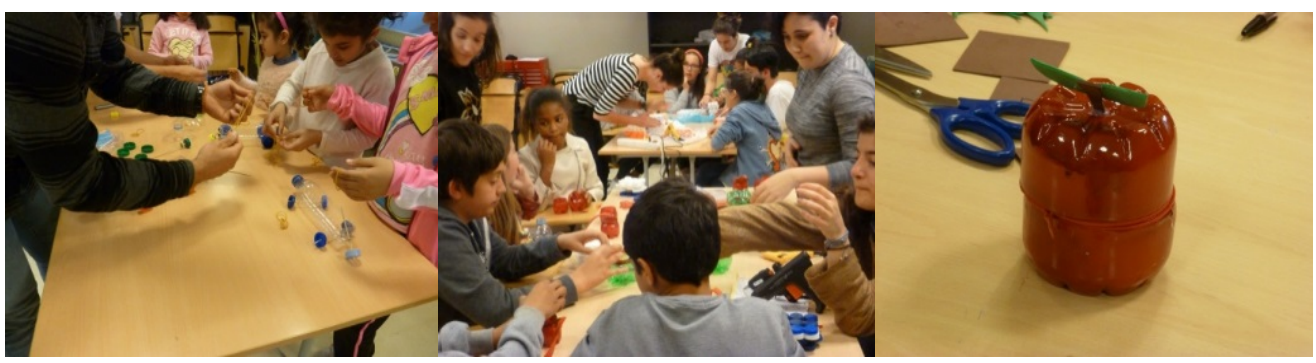

Figura 2. Fotos do taller de reutilización cos/oas nenos/as 
Actividade 2: Adultos "Taller de emprego"

Os estudantes implicados dividiron 0 taller en dúas partes, na primeira parte máis teórica introduciron aos usuarios diferentes conceptos sobre materiais plásticos, faláronlles de identificación e separación dos mesmos e de reciclado, reutilización e revalorización, así coma de xestión de residuos. Nesta primeira parte introduciron dúas prácticas de identificación e separación para facer máis amena a charla. Na segunda parte do taller fabricáronse lámpadas con materiais reciclados, concretamente bolsas de lixo e culleres de café. Na Figura 3 poden verse distintos momentos da actividade. Tamén se visitou cos usuarios, Sogama para que puidesen ver in situ a aplicación nunha empresa dos conceptos traballados no curso.

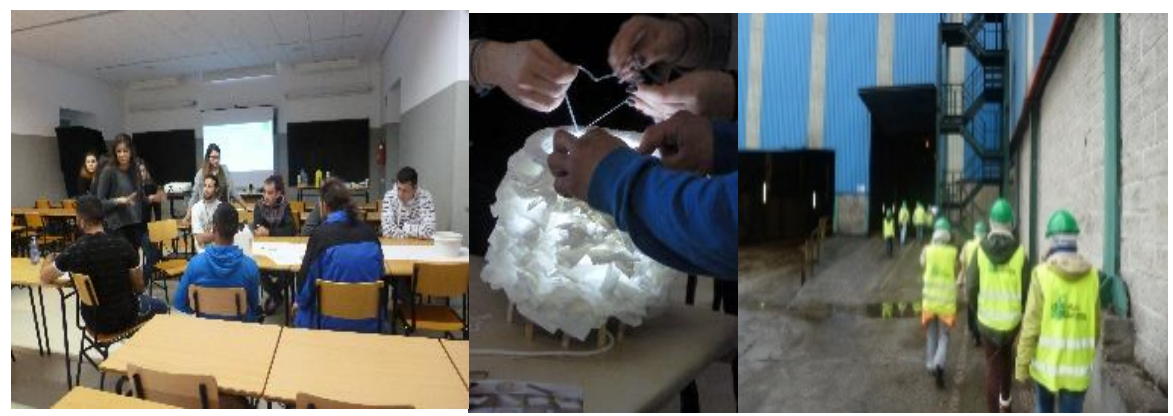

Figura 3. Fotos da actividade cos adultos

\section{Actividade 3: Mulleres árabes}

Os estudantes implicados nesta actividade tiñan como misión educar estas mulleres, que levaban pouco tempo no noso país, en valores de convivencia social no que respecta ao medioambiente. Os estudantes tiveron un problema con estas usuarias, pois descoñecían 0 escaso dominio do idioma que estas tiñan ata o mesmo día do taller. As mulleres falaban bastante ben español, sen embargo non sabían ler, nin escribir practicamente no noso idioma. Debido a isto, os estudantes tiveron que modificar in situ o seu discurso e a planificación para que puidesen comprendelos e foron capaces de facerlles entender a importancia de reducir, reutilizar e reciclar, explicáronlles a separación de residuos en distintos contedores e como podían facelo nas súas casas e a repercusión que iso podía ter na sociedade. Os estudantes 
fixeron xogos e interaccionaron moito con elas, comprobando en todo momento que estaban a entendelos. Incluso lles mostraron como funciona a impresión 3D, unha ferramenta actual no desenvolvemento do deseño industrial. Estas mulleres participaron na visita a Sogama tamén. Na Figura 4 poden verse algunhas imaxes da sesión.

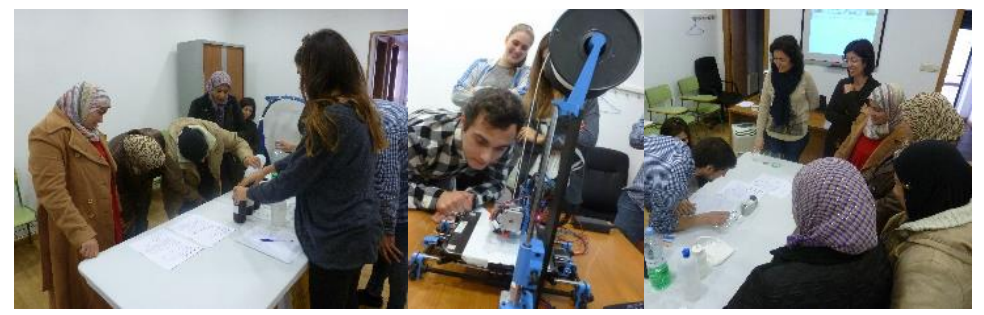

Figura 4. Fotos da actividade coas mulleres árabes

\section{RESULTADOS}

Da análise de todas as evidencias recollidas durante as distintas actividades (enquisas, reflexións, reunións, rúbrica) puideron extraerse os principais resultados da avaliación das actividades.

Dende o punto de vista académico, todos os estudantes adquiriron as competencias da parte práctica da materia e que aparecen na rúbrica da Táboa 2. 0 feito de ter que aprender para ensinar, fai que os estudantes implicados nas actividades ApS afondasen máis nos conceptos da materia e que a súa implicación no proxecto sexa maior, o que se ve reflexado no grao de consecución de competencias.

Dende o punto de vista cuantitativo, analizáronse os resultados das enquisas realizadas aos estudantes e aos usuarios. Ambos grupos mostraron a súa satisfacción en todos os aspectos da actividade como se pode ver na Figura 5 coa práctica totalidade de respostas "Totalmente de acordo" ou "De acordo". Cabe sinalar que a enquisa para os usuarios e para os/as nenos/as se simplificou para facilitarlles a comprensión da mesma, tendo en conta o nivel académico dos/as nenos/as, dos adultos e o escaso dominio do idioma das mulleres árabes. 
Aínda que na Figura 5 só se presentan os resultados para 0 grupo dos adultos as respostas foron moi similares en todos os casos.
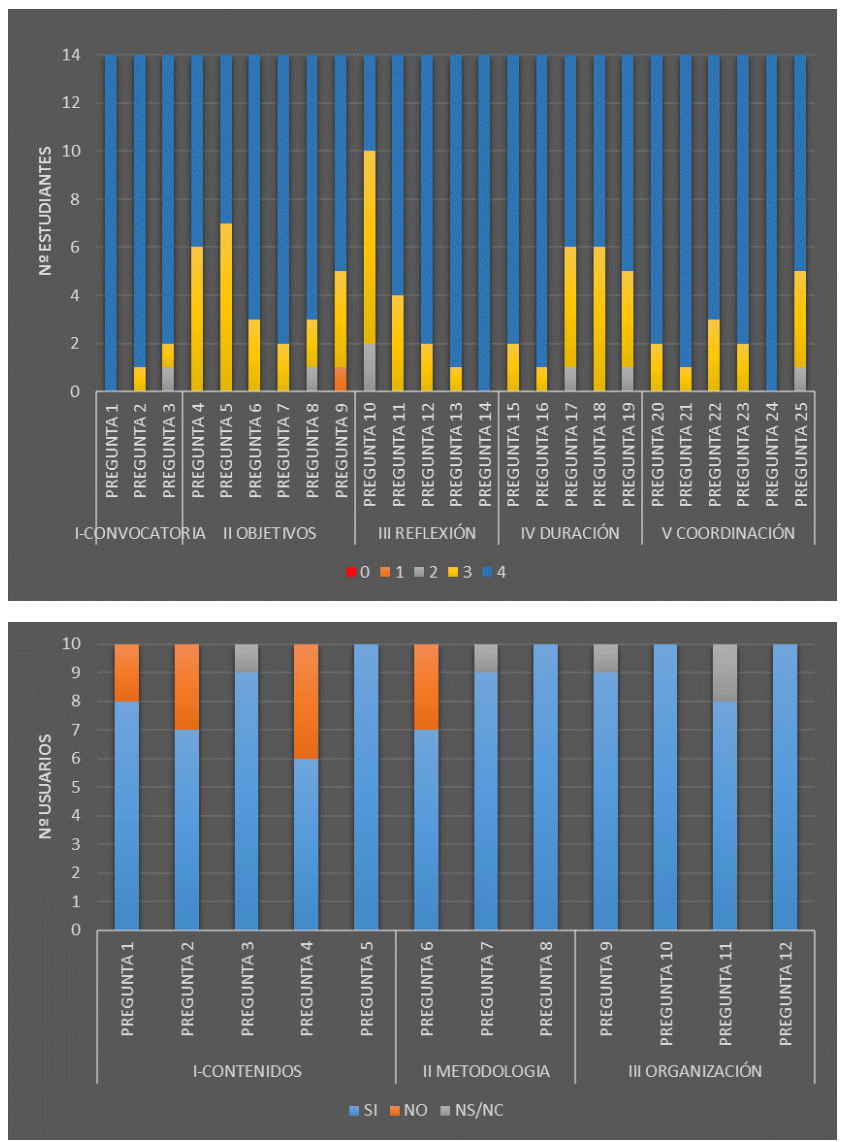

Figura 5. Resultados das enquisas a) estudantes; b) adultos "Taller de emprego"

Dende 0 punto de vista cualitativo, das reunións realizadas con tódolos implicados, constatouse a enorme satisfacción de todos os axentes, de feito a entidade quere continuar a actividade de cara os próximos cursos. Os estudantes só encontraron como punto débil o non ter sabido, por adiantado, os problemas de idioma das mulleres árabes. Acordouse coa 
entidade que sería moi importante de cara a seguintes convocatorias ter información detallada do perfil dos usuarios participantes.

Algunhas das reflexións recollidas dos estudantes foron:

"Cando tes que ensinar aprendes moito mais. 0 aprendizaxe-servizo é necesario para a nosa formación" (Estudante grupo adultos)

"Gustaríame destacar os problemas de comunicación que tivemos coas mulleres árabes. Creo que nos adaptamos moi ben á situación" (Estudante grupo mulleres árabes)

"É moi difícil manter a atención do público, agora entendo aos meus profesores" (Estudante grupo nenos/as)

En canto aos usuarios:

"Gustoume moito coñecer aos universitarios. Ao mellor eu tamén podo ser coma eles" (Nenos/as)

"Os estudantes tiveron moita paciencia para falar con nós" (Mulleres árabes)

"Pareceume moi útil a información para a busca de emprego e para a nosa vida diaria" (Adultos Taller emprego)

"Non me importaría traballar no sector do reciclado que non coñecía" (Adultos taller de emprego).

Do análise destas reflexións pode verse que os estudantes valoran de xeito moi positivo o feito de aprender para ensinar. Segundo dicía William Glasser na súa pirámide de aprendizaxe, aprendemos: 0 10\% do que lemos, $020 \%$ do que oímos, o 30\% do que vemos, $050 \%$ do que vemos e oímos, $070 \%$ do que discutimos con outros, o $80 \%$ do que facemos e $095 \%$ do que ensinamos a outros. Polo tanto, é obvio que o feito de ter que aprender para ensinar fai que os estudantes aprendan e adquiran as competencias que se lles esixen moito antes cando están envoltos nunha metodoloxía na que se fomente que eles teñan que ensinar como é o caso do ApS. 
Apreciase ademais que os estudantes melloran en autoestima ao enfrontarse a situacións inesperadas e ser eles mesmos os responsables de solucionar o problema (o caso das mulleres árabes).

No grupo dos nenos/as e das mulleres árabes puido observarse tamén unha grande empatía con eles por parte dos estudantes que se esforzaron moitísimo en facerse entender e en captar a súa atención

En canto aos usuarios, das reflexións dos nenos/as pode extraerse o entusiasmo polo coñecemento que tiveron despois da sesión e das dos adultos, o valor que lle deron a todo 0 aprendido cos estudantes. En xeral, a experiencia resultou positiva para os usuarios non só dende o punto de vista académico ou profesional, senón tamén dende o punto de vista persoal.

\section{CONCLUSIÓNS}

0 aprendizaxe-servizo resultou ser unha ferramenta metodolóxica moi útil, xa que se fomenta a aprendizaxe baseado na experiencia e a reciprocidade na aprendizaxe (os estudantes aprenden uns dos outros). Co ApS conséguese formar aos estudantes non só en conceptos ou competencias, senón tamén en valores (a empatía e a preocupación polos grupos desfavorecidos son patentes nas reflexións recollidas dos estudantes). 0 estudante, ao ser protagonista principal da actividade, xa que ten que deseñala e levala a cabo, gaña en autoestima e autoconfianza, así coma, en autonomía para a resolución de problemas. Ademais, o feito de ter que aprender para ensinar, fai que os estudantes implicados no ApS adquiran os conceptos e as competencias con máis profundidade e con outro significado que aqueles que non participan na actividade. Para o profesor a avaliación de competencias resulta máis sinxela, xa que se pode observar ao estudante durante todo o proceso de aprendizaxe. Favorecese a autoavaliación do estudante, que é consciente dos erros que comete en cada punto da tarefa e de que ten que corrixilos. Por último, o feito de que os estudantes destaquen 
que o ApS tería que ser parte fundamental na súa formación, di moito da responsabilidade que os alumnos senten trala experiencia coma cidadáns responsables e axentes do cambio.

\section{REFERENCIAS}

- Dienhart, C.; Maruyama, G.; Snyder, M., Furco, A.; McKay, M.S.; Hirt, L \& Huesman, R. (2016). The impacts of mandatory service on students in service-learning classes. Journal of Social Psychology, 156 (3), pp. 305-309.

- Ferrán-Zubillaga, A. \& Guinot-Viciano, C. (2012). Aprendizaje-Servivio: propuesta metodológica para trabajar competencias. Portularia, 12, pp. 187-195.

- Latib, A.A.; Amin, N.F., Saud, M.S. \& Kamin, Y. (2017). Impact of Service Learning Program to the University and the Community. Advanced Science Letters, 23, pp596-599.

- Puig, J., Martín, X. \& Battle, R. (2008). Cómo iniciar un proyecto de aprendizaje y servicio solidario. Guía Zerbikas. Bilbao: Fundación Zerbikas

- Rubio, L. (2009). El aprendizaje en el aprendizaje servicio. En J.M. Puig (Coord.), Aprendizaje Servicio (ApS). Educación y compromiso cívico, pp. 91-105, Barcelona: Graó.

- UNESCO (1998). Conferencia mundial sobre Educación Superior. La educación superior en el siglo XIX. Visión y acción. París.

- UNESCO (2009). Comunicado Conferencia Mundial sobre la Educación Superior: La nueva dinámica de la educación superior y la investigación para el cambio social y el desarrollo. París. 